\title{
Genotoxic stress/p53-induced DNAJB9 inhibits the pro-apoptotic function of p53
}

\author{
HJ Lee ${ }^{1}, \mathrm{JM} \mathrm{Kim}^{1}, \mathrm{KH} \mathrm{Kim}^{2}$, Jl Heo ${ }^{3}$, SJ Kwak${ }^{4}$ and JA Han ${ }^{*, 1}$
}

DNAJB9 is a recently isolated member of the molecular chaperone gene family, whose precise function is largely unknown. In the present study, we have identified DNAJB9 as an inducible gene of the tumor suppressor p53. DNAJB9 expression was induced by p53 or genotoxic stress in a p53-dependent manner, which was mediated by the Ras/Raf/ERK pathway. In addition, depletion of DNAJB9 by using siRNAs greatly increased genotoxic stress/p53-induced apoptosis, suggesting that DNAJB9 inhibits the pro-apoptotic function of $\mathrm{p53}$. We also found that DNAJB9 physically interacts with p53 through its $\mathrm{J}$ domain, through which it inhibits the pro-apoptotic function of p53. Moreover, DNAJB9 colocalized with p53 in both cytoplasm and nucleus under genotoxic conditions. Together, these results demonstrate that DNAJB9 is a downstream target of p53 that belongs to the group of negative feedback regulators of $\mathrm{p} 53$.

Cell Death and Differentiation (2015) 22, 86-95; doi:10.1038/cdd.2014.116; published online 22 August 2014

The tumor suppressor p53 is activated upon DNA damage and inhibits cell proliferation by inducing cell cycle arrest, senescence or apoptosis. p53 exerts these actions principally via binding to the consensus binding motifs in the genome, thereby activating the transcription of its target genes. It has been known that, among the target genes, p21 Cip1/WAF1 mediates cell cycle arrest while apoptosis is mediated by Bax, DR5, IGF-BP3, NOXA, PERP, Pidd or PUMA. ${ }^{1-7}$

Intriguingly, another group of target genes have been reported to inhibit p53 function and to act as negative feedback regulators of $\mathrm{p} 53$, which include COP1, cyclooxygenase-2 (COX-2), DDR1, HB-EGF, Mdm2 and Pirh2. The COP1, Mdm2 and Pirh2, direct transcriptional targets of p53, promote degradation of p53 via their E3 ubiquitin ligase activity, thereby inhibiting p53 transcriptional activity and p53-dependent cell cycle arrest and apoptosis. ${ }^{8-10}$ DDR1 is another direct transcriptional target of p53 and is able to protect mouse embryonic fibroblasts (MEFs) and HCT116 cells from apoptosis caused by $\gamma$-radiation and doxorubicin. ${ }^{11}$ COX-2 is indirectly induced by p53-mediated activation of the Ras/Raf/ ERK pathway and inhibits apoptosis caused by genotoxic stress in normal human epithelial cells, fibroblasts and endothelial cells. ${ }^{12,13} \mathrm{HB}-\mathrm{EGF}$ is induced by DNA damage in a p53-dependent manner and inhibits $\mathrm{H}_{2} \mathrm{O}_{2-}$ and mitomycin C-induced apoptosis in MCF-7 cells. ${ }^{14,15}$ These negative feedback regulators of p53 have been thought to protect cells from fatal stresses resulting from p53 activation. ${ }^{12}$

Molecular chaperones are specialized proteins that bind to substrate proteins and facilitate their proper folding, unfolding, translocation or degradation. In most organisms including humans, heat shock protein 70s (Hsp70s) are major chaperones, whose activity is regulated by co-chaperones such as DNAJ proteins. DNAJ proteins bind directly to Hsp70s to stimulate their ATPase activity, leading to the stabilization of interactions between Hsp70s and substrate proteins. ${ }^{16}$ At least 41 DNAJ proteins have been identified in the human genome, all of which have a conserved 70-amino acid (aa) sequence, the $\mathrm{J}$ domain, which is essential for binding to Hsp70s and stimulation of their ATPase activity. ${ }^{17}$

DNAJB9, also known as Mdg-1 or ERdj4, is a member of the DNAJ protein family. ${ }^{17,18}$ It is located in the endoplasmic reticulum (ER), where it acts as a co-chaperone for $\mathrm{BiP}$, the ER member of the Hsp70s. ${ }^{19}$ DNAJB9 has been shown to be induced by external stimuli including heat, methanol, ethanol, sodium chloride, tunicamycin and thapsigargin. ${ }^{19-22}$ In addition, it has been reported that DNAJB9 inhibits tunicamycininduced cell death in SK-N-SH cells. ${ }^{21}$ The cellular function of this DNAJ protein, however, remains largely unknown.

In the present study, we show that DNAJB9 is an inducible gene of p53 under genotoxic conditions. DNAJB9 expression is induced by p53 in response to DNA damage, which is mediated by the Ras/Raf/ERK pathway. In addition, we present evidence that DNAJB9 inhibits the pro-apoptotic function of $p 53$ through a physical interaction with p53. These results suggest that DNAJB9 is a downstream target of p53 and acts as a negative feedback regulator of p53 under genotoxic conditions.

\section{Results}

DNAJB9 is induced by p53 under genotoxic conditions. We have previously observed that the transcript for DNAJB9 is increased in response to p53 expression in DNA microarray analyses using EJ-p53, which is a stable cell line

${ }_{1}^{1}$ Department of Biochemistry and Molecular Biology, Kangwon National University School of Medicine, Chuncheon, South Korea; ${ }^{2}$ Institute for Systems Biology, Seattle, WA, USA; ${ }^{3}$ Department of Biochemistry, College of Medicine, Hallym University, Chuncheon, South Korea and ${ }^{4}$ Department of Biochemistry, College of Medicine, Dankook University, Cheonan, South Korea

${ }^{*}$ Corresponding author: JA Han, Department of Biochemistry and Molecular Biology, Kangwon National University School of Medicine, Hyoja-2-dong, Chuncheon 200-701, South Korea. Tel: +82 33250 8832; Fax: +82 33250 8807; E-mail: gshja @kangwon.ac.kr

Abbreviations: Ad, adenovirus; COX-2, cyclooxygenase-2; ER, endoplasmic reticulum; Hsp, heat shock protein; MEF, mouse embryonic fibroblast

Received 06.12.13; revised 11.6.14; accepted 08.7.14; Edited by B Zhivotovsky; published online 22.8.14 
that expresses p53 under the control of a tetracyclineregulated promoter. ${ }^{12,23}$ To investigate whether DNAJB9 is indeed an inducible gene of p53, we first monitored DNAJB9 expression in EJ-p53 cells by Northern and Western blot analysis. Removal of tetracycline from EJ-p53 cells resulted in an increase of p53 levels as well as p21, a known p53 target, as expected. In this state, the amount of DNAJB9 mRNA and protein was found to increase substantially (Figure 1a), indicating that DNAJB9 is induced by exogenous p53.

p53 is activated in response to DNA damage. ${ }^{24}$ Therefore, to examine whether DNAJB9 is induced by endogenous p53, we monitored DNAJB9 expression upon DNA damage in SK-N-SH and U2OS cells harboring wild-type p53. When we administered doxorubicin, a genotoxic drug, to these cells, it was observed that both mRNA and protein levels of DNAJB9 was increased substantially (Figures $1 b$ and $c$ ). The amount of p53 and p21 was also increased by doxorubicin treatment, confirming that DNA damage occurred and p53 was activated by doxorubicin treatment in these cells (Figures $1 b$ and $c$ ). Moreover, the quantity of DNAJB9 was also increased by other genotoxic drugs including actinomycin $\mathrm{D}$, etoposide and mitomycin $\mathrm{C}$ in SK-N-SH cells (Figures $1 \mathrm{~d}-\mathrm{g}$ ). These results suggest that DNAJB9 is induced by endogenous p53 under genotoxic conditions.

To verify the involvement of p53 in the induction of DNAJB9 under genotoxic conditions, we analyzed DNAJB9 expression in $p 53(+/+)$ and $p 53(-/-)$ MEFs. The amount of DNAJB9 mRNA and protein was prominently increased by doxorubicin treatment in $p 53(+/+)$ MEFs, which was not observed in p53(-/ - ) MEFs (Figure 1h). The p53 and p21 levels were elevated in response to doxorubicin treatment in $p 53(+/+)$ MEFs but not in p53 $(-/-)$ MEFs, confirming that p53 was activated only in $p 53(+/+)$ MEFs (Figure $1 \mathrm{~h})$. These results demonstrate that the induction of DNAJB9 is dependent on p53 activation, verifying that DNAJB9 is induced by p53 under genotoxic conditions.

Together, these data suggest that DNAJB9 is indeed an inducible gene of p53 under genotoxic conditions.

DNAJB9 is indirectly induced by p53 through the Ras/Raf/ERK pathway. We next investigated the mechanism by which DNAJB9 is induced by p53. For this purpose, we first tested a possibility that DNAJB9 is a direct transcriptional target of p53. According to the PubMed database, the gene encoding human DNAJB9 is located on the chromosome 7
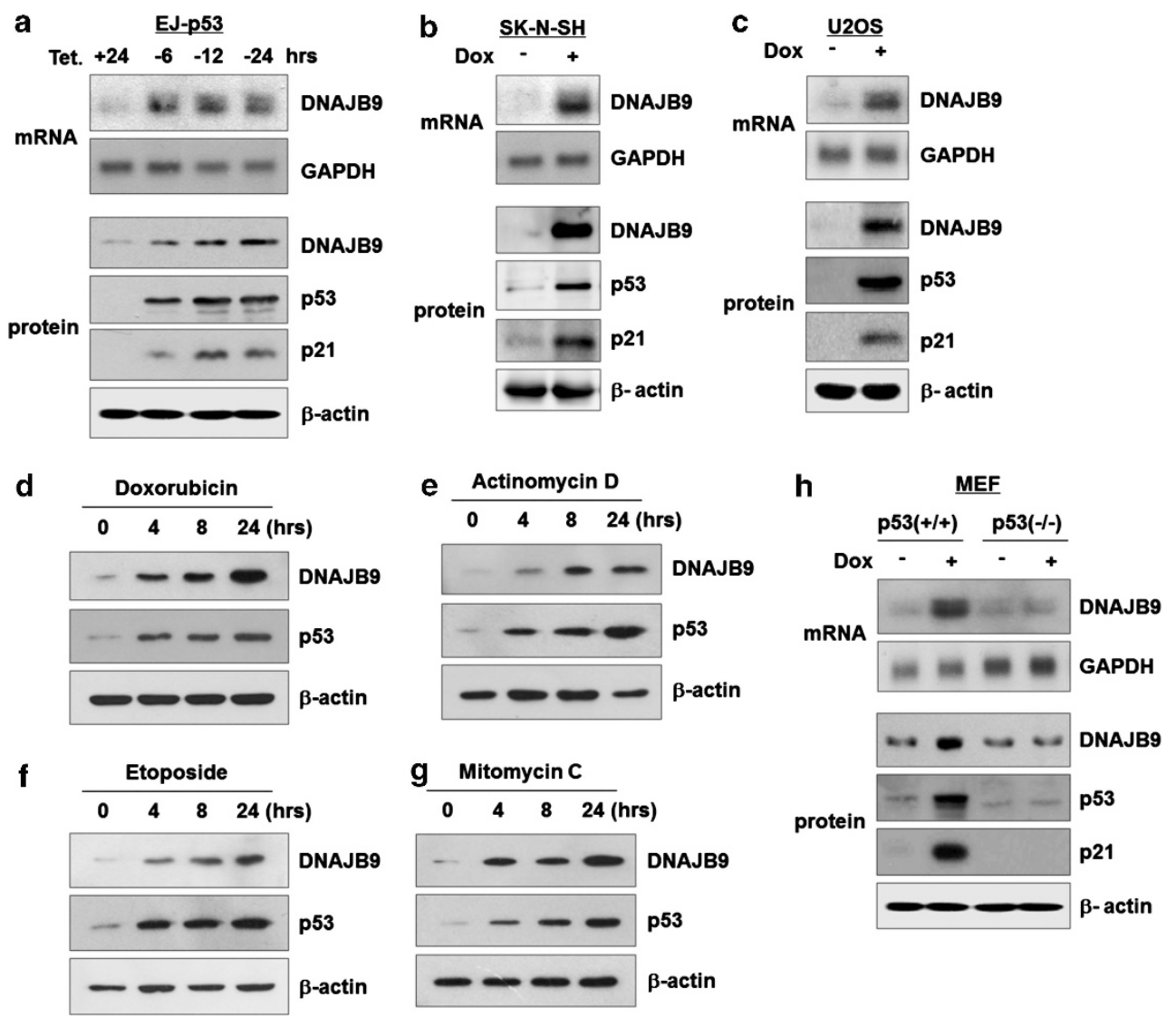

Figure 1 DNAJB9 is induced by p53 under genotoxic conditions. (a) EJ-p53 cells were cultured in the presence of $1 \mu \mathrm{g} / \mathrm{ml}$ of tetracycline (Tet). To induce p53 expression, tetracycline was removed and cells were cultured for the indicated times. Total RNA and protein samples were prepared and subjected to Northern and Western blot analysis, respectively. GAPDH and $\beta$-actin were used as loading controls. SK-N-SH (b) and U2OS (c) cells were treated with $1 \mu$ M of doxorubicin (Dox) for $8 \mathrm{~h}$. Northern and Western blot analyses were performed. Doxorubicin $(1 \mu \mathrm{M})(\mathbf{d})$, actinomycin D $(10 \mathrm{ng} / \mathrm{ml})(\mathbf{e})$, etoposide $(20 \mu \mathrm{M})(\mathbf{f})$ or mitomycin $\mathrm{C}(20 \mu \mathrm{M})(\mathbf{g})$ was administered to SK-N-SH cells. Cells were harvested at the indicated times and subjected to Western blot analysis. $(\mathrm{h}) \mathrm{p} 53(+/+)$ and $p 53(-/-)$ MEFs were treated with $1 \mu \mathrm{M}$ of doxorubicin for $8 \mathrm{~h}$. Total RNA and protein samples were prepared and subjected to Northern and Western blot analysis 
ranging from the nucleotide number 108210189 to 108215294. To find the p53-binding motifs in the promoter or intron regions of DNAJB9, we analyzed the $3 \mathrm{~kb}$ upstream region (108207188-108210188) and the gene itself by using the AliBaba2 program. The results showed that there are no p53binding motifs in the $3 \mathrm{~kb}$ upstream region as well as in the DNAJB9 gene (Supplementary Figures $1 \mathrm{a}$ and b), suggesting that DNAJB9 is not a direct transcriptional target of p53.

It has been previously reported that the Ras/Raf/ERK pathway is activated by p53 under genotoxic conditions. ${ }^{14}$ In addition, we have previously shown that the Ras/Raf/ERK pathway mediates the induction of COX-2 by $p 53 .^{12}$ Therefore, we tested the possibility that the MAPK pathway is involved in the p53-induced DNAJB9 expression in genotoxic conditions. The amount of DNAJB9 and phosphorylated ERK1/2 (p-ERK1/2) were increased dramatically by doxorubicin treatment in SK-N-SH and U2OS cells, which was remarkably attenuated by the pretreatment of a MEK1/2 inhibitor, U0126 (Figures $2 a$ and d). On the contrary, the pretreatment of SB203580 (a p38-MAPK inhibitor) or SP600125 (a JNK inhibitor) did not affect the DNAJB9 expression in the presence of doxorubicin (Figures $2 \mathrm{~b}$ and c), suggesting that the p38 and JNK pathway are not involved in the p53-induced DNAJB9 expression. These results suggest that the MEK/ERK pathway is involved in the induction of DNAJB9 by p53 under genotoxic conditions.

To confirm the involvement of the Ras/Raf/ERK pathway in the induction of DNAJB9 by p53, we analyzed the effect of a dominant-negative (DN) mutant form of Ras (H-RasN17) or Raf-1 (K375M) on p53-induced DNAJB9 expression.
In EJ-p53 cells, overexpression of p53 by tetracycline removal increased the amount of DNAJB9 and p-ERK1/2, which was almost completely abolished by a transient transfection of DN-Ras or DN-Raf-1 (Figure 2e). These results confirm that the Ras/Raf pathway is involved in the induction of DNAJB9 by $\mathrm{p} 53$.

All these results suggest that the Ras/Raf/ERK pathway mediates the induction of DNAJB9 by p53 under genotoxic conditions.

DNAJB9 inhibits the pro-apoptotic function of p53 under genotoxic conditions. We next investigated the physiological role of DNAJB9 that has been induced by p53 under genotoxic conditions. For this purpose, we generated three siRNAs specific for DNAJB9 (si-JB9 \#1, \#2 and \#3) and a scrambled siRNA (si-control) as a control, and confirmed that all three siRNAs are effective in preventing DNAJB9 expression (Supplementary Figure 2a).

We transfected si-JB9 \#1 and \#2 as well as si-control into SK-N-SH and U2OS cells, and then treated cells with doxorubicin. After $24 \mathrm{~h}$, the sub- $\mathrm{G}_{1}$ apoptotic cell population was measured by flow cytometry. The data showed that the doxorubicin treatment increased sub- $\mathrm{G}_{1}$ cell population in sicontrol-transfected cells as compared with DMSO (the vehicle) treatment (from 3.1 to $7.5 \%$ in SK-N-SH; from 1.4 to $12.2 \%$ in U2OS), which was dramatically enhanced in si-JB9transfected SK-N-SH cells (23.1\% for \#1 and $21.2 \%$ for \#2) and U2OS cells (29.1\% for \#1 and 29.0\% for \#2; Figures 3a and $b$ ). These results suggest that DNAJB9 acts as a survival factor under genotoxic conditions.
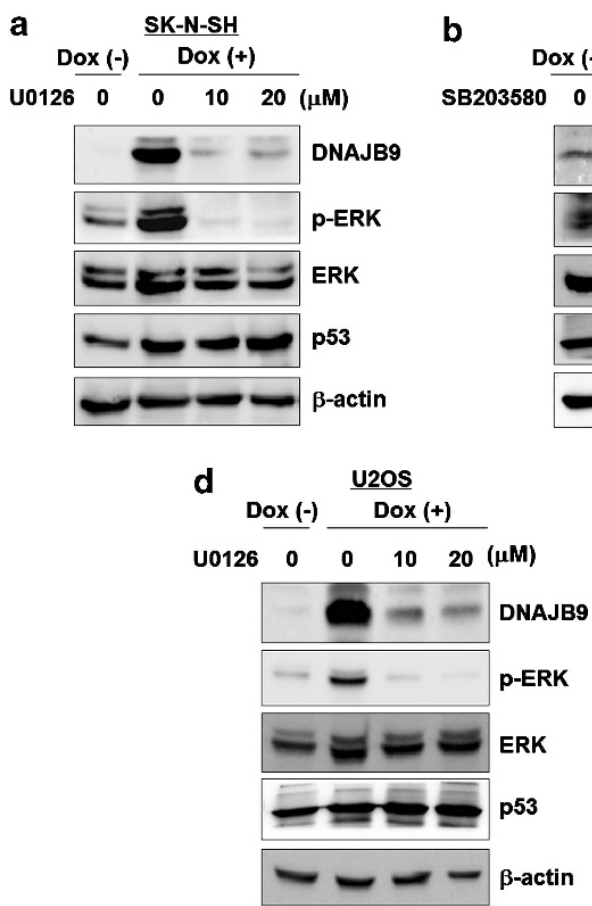
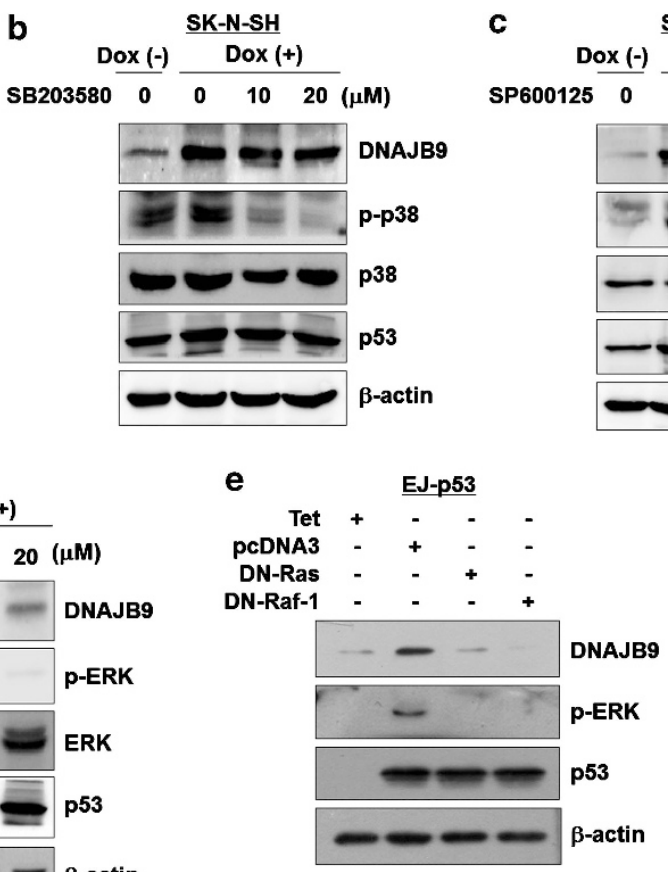

Figure 2 DNAJB9 is induced by p53-mediated activation of the Ras/Raf/ERK pathway. SK-N-SH cells were pretreated with U0126 (a), SB203580 (b) or SP600125 (c) at the concentrations of 0 (DMSO only), 10 or $20 \mu \mathrm{M}$ for $1 \mathrm{~h}$. Cells were then treated with $1 \mu \mathrm{M}$ of doxorubicin (Dox) for $8 \mathrm{~h}$. Protein samples were prepared and analyzed by Western blotting. $\beta$-actin was used as a loading control. (d) U2OS cells were pretreated with U0126 for $1 \mathrm{~h}$, and then treated with $1 \mu \mathrm{M}$ of doxorubicin for $8 \mathrm{~h}$. Protein samples were analyzed by Western blotting. (e) EJ-p53 cells grown in the medium containing $1 \mu \mathrm{g} / \mathrm{ml}$ of tetracycline (Tet) were transfected with DN-Ras, DN-Raf-1 or an empty vector (pcDNA3). After tetracycline removal, cells were further cultured for $24 \mathrm{~h}$ and subjected to Western blot analysis 
On the other hand, the amounts of $p 53$, bax and cleaved caspase-3 were increased by doxorubicin treatment in si-control-transfected SK-N-SH and U2OS cells as compared with DMSO (Figures $3 c$ and $d$ ), showing that the p53dependent and caspase-3-mediated apoptotic pathway was activated by doxorubicin treatment in these cells. In addition, si-JB9 \#1 and \#2 elevated the amount of bax and cleaved caspase-3 as compared with si-control in the presence of doxorubicin (Figures $3 \mathrm{c}$ and $\mathrm{d}$ ), suggesting that DNAJB9 inhibits the p53-dependent and caspase-3-mediated apoptosis under genotoxic conditions.

To verify that DNAJB9 inhibits the p53-dependent apoptosis under genotoxic conditions, we evaluated effects of the siRNAs on doxorubicin-induced apoptosis in $p 53(+/+)$ and p53 $(-/-)$ MEFs. Doxorubicin treatment increased apoptotic rates in both si-control-transfected $p 53(+/+)$ MEFs (from 1.4 to $6.0 \%$ ) and $p 53(-/-)$ MEFs (from 2.0 to $10.4 \%$ ) as compared with DMSO treatment (Figures $3 e$ and f). The si-JB9 \#1 and \#2 enhanced the apoptotic rates in p53 $(+/+)$ MEFs as compared with si-control in the presence of doxorubicin $(25.2 \%$ for \#1; $26.1 \%$ for \#2; Figure $3 e$ ), while the apoptotic rates were not enhanced by the si-JB9s in p53 (-/ - ) MEFs (10.4\% for \#1; 10.3\% for \#2; Figure 3f). We also observed that the si-JB9s did not enhance apoptotic rates in the presence of doxorubicin in another p53-null cell line, H1299 (Figure $3 \mathrm{~g}$ and Supplementary Figure 2c). These results verify that DNAJB9 inhibits the p53-dependent apoptosis under genotoxic conditions.

To further confirm that DNAJB9 inhibits the pro-apoptotic function of p53, we evaluated the effect of siRNAs on apoptosis triggered by p53 overexpression. SK-N-SH cells were transfected with siRNAs and then infected by adenoviruses expressing p53 (Ad-p53) or green fluorescence protein (Ad-GFP) as a control. After $24 \mathrm{~h}$, cells were harvested and the apoptotic rates were measured by flow cytometry. The data showed that Ad-p53 infection triggered apoptosis in si-control-transfected cells as compared with Ad-GFP (from 1.4 to $6.8 \%$ ), which was remarkably enhanced in si-JB9-transfected cells $(20.3 \%$ for \#1 and 18.2\% for \#2; Figure 3h). In addition, si-JB9 \#1 and \#2 elevated the amount of bax and cleaved caspase- 3 as compared with si-control in the presence of Ad-p53
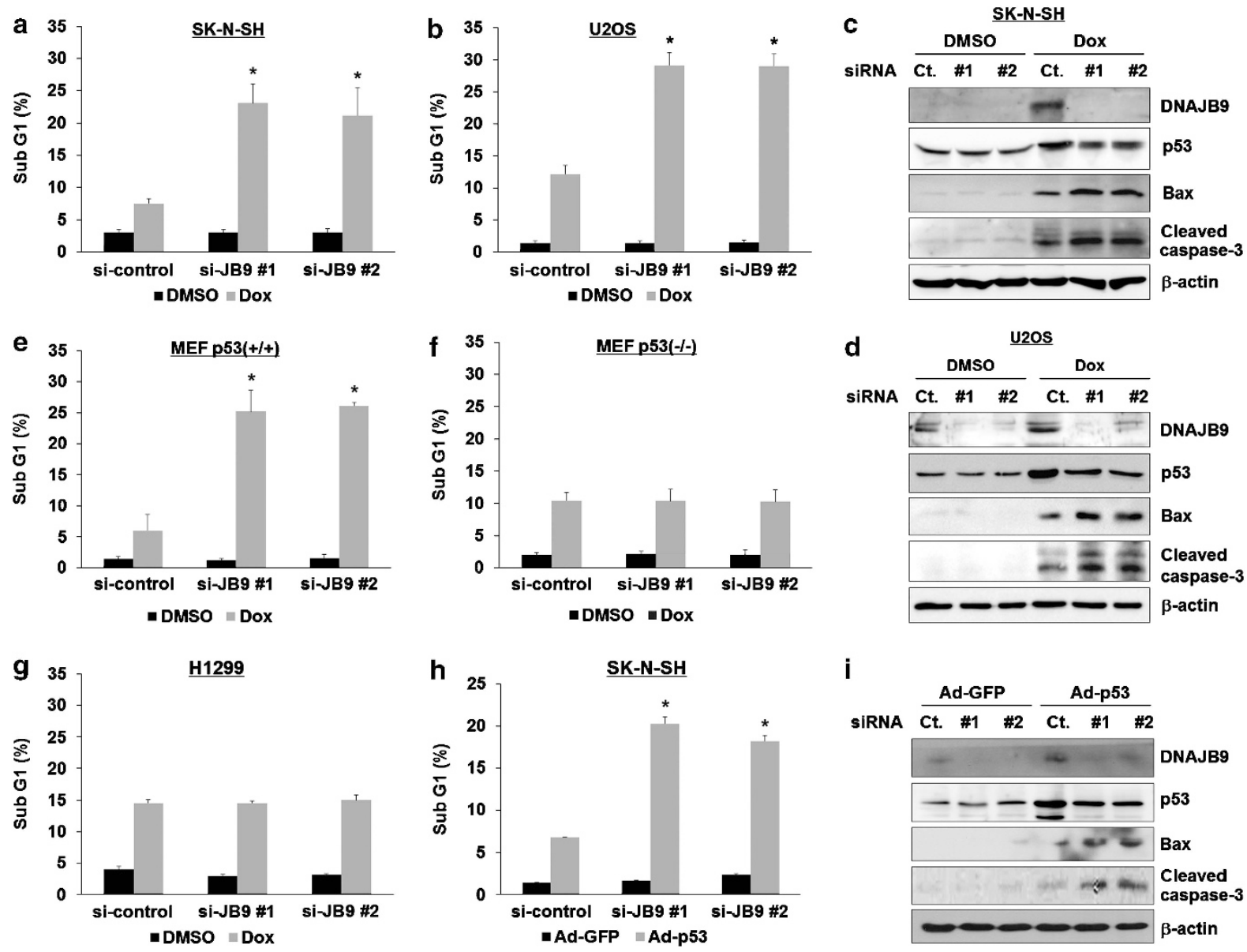

Figure 3 DNAJB9 inhibits the pro-apoptotic function of p53. SK-N-SH (a), U2OS (b), p53(+ / + ) MEFs (e), p53 $(-/-)$ MEFs (f) and H1299 (g) cells were transfected with a scrambled siRNA (si-control), si-DNAJB9 \#1 (si-JB9 \#1) or si-DNAJB9 \#2 (si-JB9 \#2). Cells were then exposed to $1 \mu$ M of doxorubicin (Dox) or DMSO (a vehicle) for $24 \mathrm{~h}$ and the sub-G $\mathrm{G}_{1}$ cell population was measured by flow cytometry. SK-N-SH (c) and U2OS (d) cells were treated as in a and $\mathbf{b}$, respectively. Cell lysates were prepared and subjected to Western blot analysis. (h) SK-N-SH cells were transfected with si-control, si-JB9 \#1 or si-JB9 \#2, and then infected by Ad-GFP or Ad-p53. After $30 \mathrm{~h}$, the sub-G cell population was measured by flow cytometry. (i) SK-N-SH cells were treated as in $\mathbf{h}$ and subjected to Western blot analysis. Data represent averages \pm S.D. $\left({ }^{\star} P<0.05\right.$ versus si-control) 
(Figure 3i). These results confirm that DNAJB9 inhibits the pro-apoptotic function of $\mathrm{p} 53$.

All these data suggest that DNAJB9 inhibits the proapoptotic function of p53 under genotoxic conditions.

DNAJB9 physically interacts with p53 through the $\mathbf{J}$ domain. DNAJB9 is a molecular chaperone whose entity is to bind to other proteins. This led us to hypothesize that DNAJB9 might inhibit the pro-apoptotic function of p53 through a physical interaction. To test this hypothesis, we performed immunoprecipitation assays in SK-N-SH and U2OS cells under the treatment of doxorubicin. The results showed that DNAJB9 was co-precipitated with p53 by an anti-p53 antibody (Figures $4 a$ and $c$ ). Consistent with this finding, p53 was co-precipitated with DNAJB9 by an antiDNAJB9 antibody (Figures $4 \mathrm{~b}$ and $\mathrm{d}$ ). These results suggest that DNAJB9 physically interacts with p53 under genotoxic conditions.

DNAJB9 consists of 223 aa, which contains an amino-terminal hydrophobic sequence (aa 7-23), a J domain (aa 24-93) and a glycine-rich domain. ${ }^{21}$ On the basis of this structural information, we generated (myc) $)_{6}$-tagged DNAJB9 and its deletion mutants designated as FL (aa 1-223), NJ (aa 1-93), N (aa 1-23), J (aa 24-93) and $\Delta \mathrm{J}$ (truncated, aa 30-93; Figure $4 \mathrm{e}$ ). SK-N-SH cells were transfected with these mycDNAJB9 plamids and then treated with doxorubicin to enrich for endogenous p53. The subsequent immunoprecipitation assays using an anti-myc antibody showed that p53 was coprecipitated with myc-DNAJB9-FL, - NJ and -J but not with myc-DNAJB9-N and $-\Delta \mathrm{J}$ (Figure 4f). Reverse immunoprecipitation assays using an anti-p53 antibody also showed that myc-DNAJB9-FL, - NJ and -J were co-precipitated with p53, but myc-DNAJB9-N and $-\Delta \mathrm{J}$ were not (Figure $4 \mathrm{~g}$ ). These results suggest that DNAJB9 interacts with p53 through the $\mathrm{J}$ domain.

DNAJB9 colocalizes and interacts with p53 in both cytoplasm and nucleus under genotoxic conditions. It has been known that the primary location of DNAJB9 is the ER whereas p53 shuttles between the cytosol and the nucleus. ${ }^{19,21}$ This raises us a question of how DNAJB9 and p53 existing in different compartments can physically
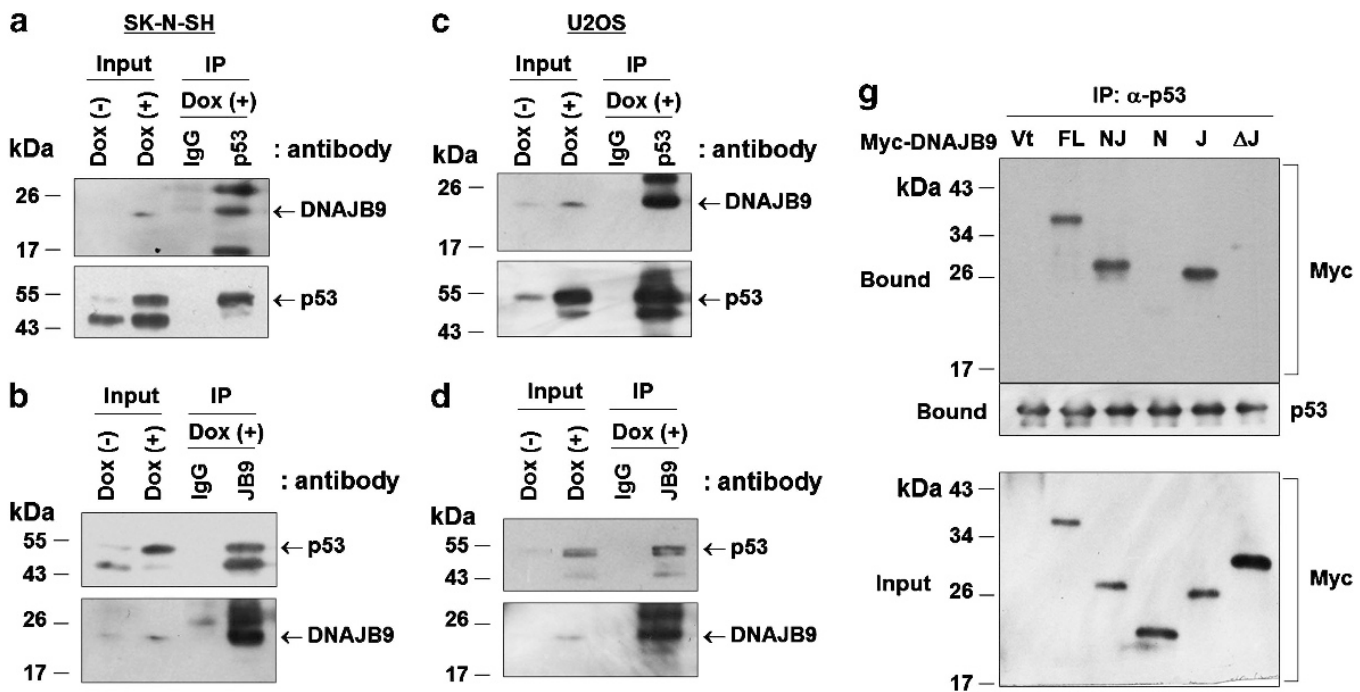

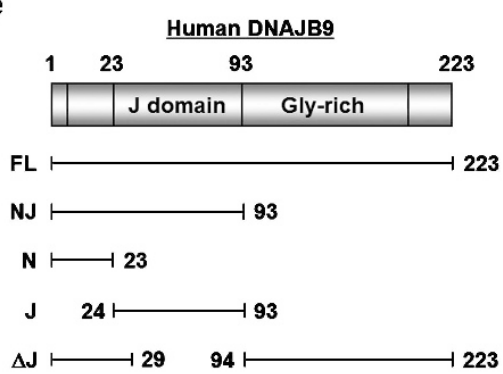

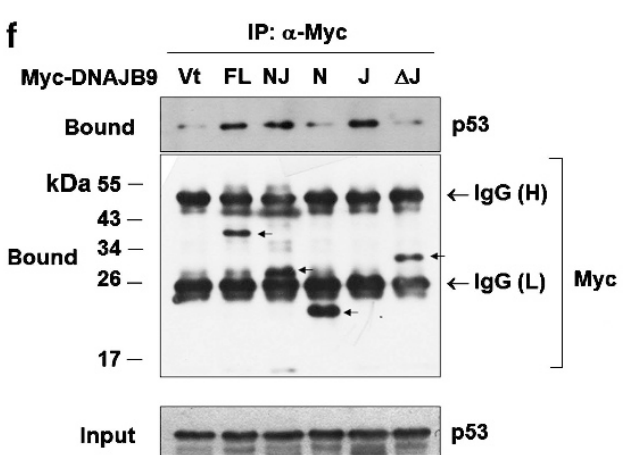

Figure 4 DNAJB9 interacts with p53 through the $\mathrm{J}$ domain. SK-N-SH (a) and U2OS (c) cells were treated with $1 \mu \mathrm{M}$ of doxorubicin (Dox) for $8 \mathrm{~h}$. Cell lysates were prepared and immunoprecipitation experiments were performed with an anti-p53 antibody (FL-393). The precipitates were subjected to Western blotting using antibodies against DNAJB9 and p53. SK-N-SH (b) and U2OS (d) cell lysates were immunoprecipitated by the anti-DNAJB9 antibody, and the precipitates were subjected to Western blotting using antibodies against p53 and DNAJB9. (e) Schematic representation of the structure of human DNAJB9 and its deletion mutants. (f and g) SK-N-SH cells were transfected with expression vectors for myc-DNAJB9 deletion mutants or an empty vector (Vt) as indicated, and then treated with $1 \mu \mathrm{M}$ of doxorubicin for $8 \mathrm{~h}$. In $\mathbf{f}$, immunoprecipitation was carried out using an anti-myc antibody, and the samples were then probed with anti-p53 or anti-myc antibodies. In $\mathbf{g}$, immunoprecipitation was carried out using an anti-p53 antibody (FL-393), and the samples were then probed with anti-myc and anti-p53 antibodies 
interact with each other. To solve this problem, we performed Western blot analysis using cytoplasmic and nuclear fractions from SK-N-SH and U2OS cells. The majority of DNAJB9 was detected in the cytoplasmic fraction in resting states. Upon doxorubicin treatment, however, the amount of DNAJB9 increased in both fractions. As for p53, it was detected mainly in the nuclear fraction in resting states and its amount was increased in both fractions by doxorubicin treatment (Figures $5 a$ and b). These results demonstrate that DNAJB9 and p53 colocalize in both cytoplasmic and nuclear fractions under genotoxic conditions.

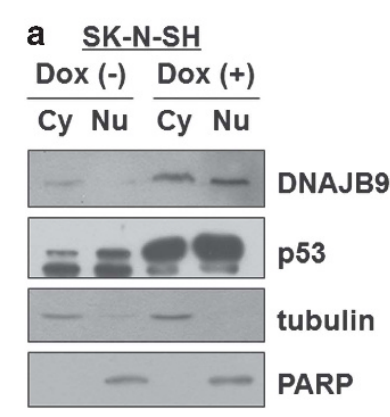

b U2OS $\frac{\mathrm{Dox}(-)}{\mathrm{Cy} \mathrm{Nu}} \frac{\mathrm{Dox}(+)}{\mathrm{Cy} \mathrm{Nu}}$

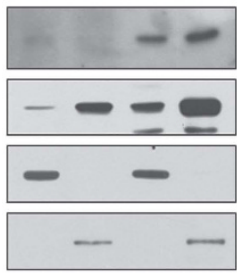

DNAJB9

p53

tubulin

PARP c

$\operatorname{Dox}(-)$
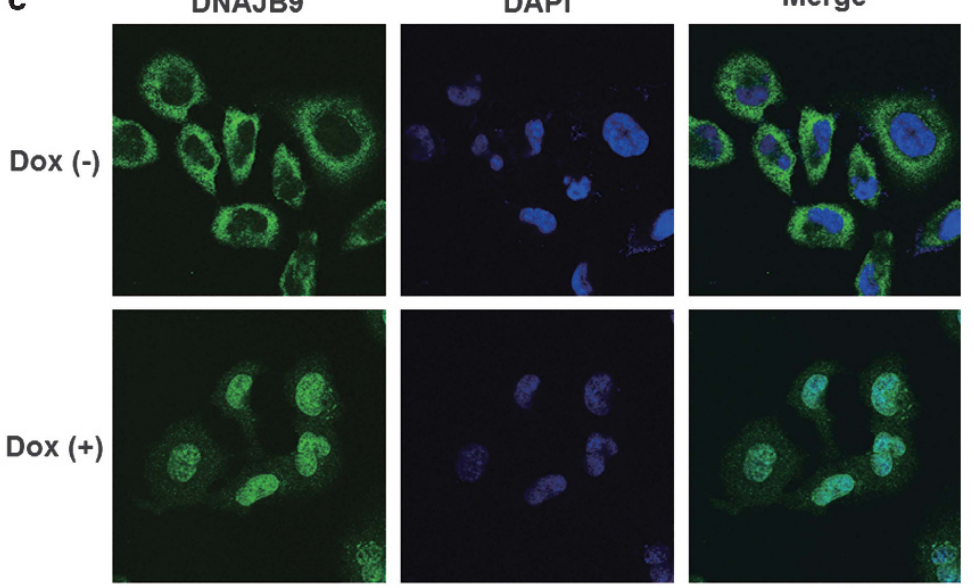

d
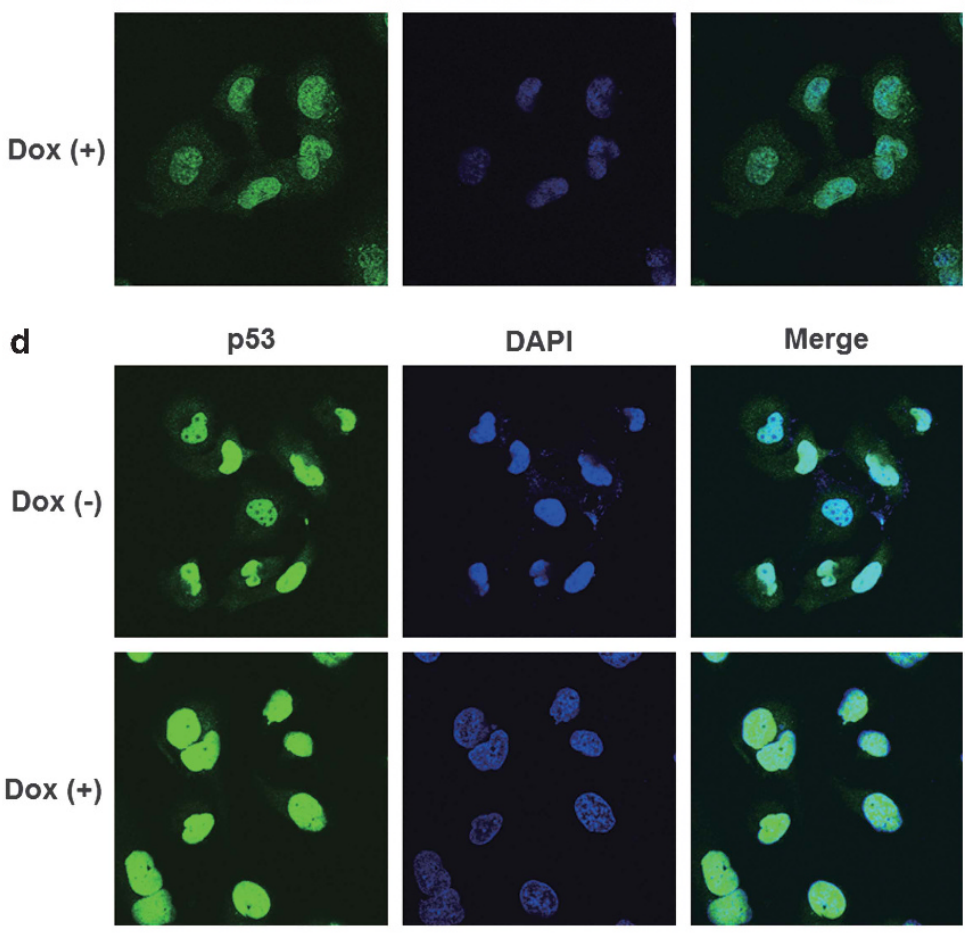
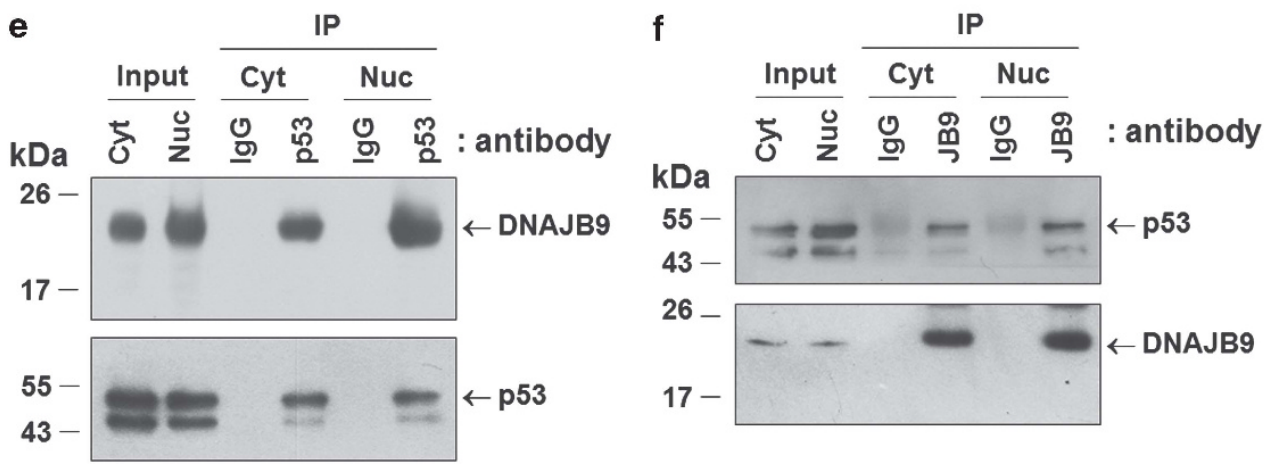

Figure 5 DNAJB9 colocalizes and interacts with p53 in both cytoplasm and nucleus under genotoxic conditions. SK-N-SH (a) and U2OS (b) cells were treated with doxorubicin $(1 \mu \mathrm{M})$ for $8 \mathrm{~h}$. Cytoplasmic (Cy) and nuclear fractions (Nu) were prepared and subjected to Western blot analysis using antibodies for DNAJB9 and p53. Tubulin and PARP were used as loading controls for the cytoplasmic and nuclear protein, respectively. (c and d) SK-N-SH cells were exposed to doxorubicin ( $1 \mu \mathrm{M})$ for $8 \mathrm{~h}$. Cells were then stained with antibodies for DNAJB9 (c) or p53 (d) as described in the Materials and Methods. DAPI was used to stain the nuclei. Images were obtained with a confocal microscope. (e and f) SK-N-SH cells were treated with doxorubicin for $8 \mathrm{~h}$ and then cytoplasmic and nuclear fractions were prepared. In e, immunoprecipitation was carried out using an anti-p53 antibody (FL-393), and the samples were probed with anti-DNAJB9 or anti-p53 antibodies. In f, immunoprecipitation was carried out using an anti-DNAJB9 antibody, and the samples were probed with anti-p53 and anti-DNAJB9 antibodies 
In confocal microscopy, DNAJB9 was detected mainly in the perinuclear region in resting states, which was consistent with the previous report. ${ }^{21}$ Intriguingly, however, DNAJB9 was detected in the cytoplasm dispersedly as well as in the nucleus under doxorubicin treatment (Figure 5c). As for p53, it was mainly detected in the nucleus while small amount of p53 was detected in the cytoplasm in resting states. The nuclear localization of p53 became more prominent under the treatment of doxorubicin (Figure $5 \mathrm{~d}$ ). These results demonstrate that DNAJB9 and p53 colocalize in both cytoplasm and nucleus under genotoxic conditions.

We then performed immunoprecipitation assays using cytoplasmic and nuclear fractions from SK-N-SH cells treated with doxorubicin. The results showed that DNAJB9 was coprecipitated with $\mathrm{p} 53$ by an anti-p53 antibody in both fractions (Figure 5e). Reversely, p53 was co-precipitated with DNAJB9 by an anti-DNAJB9 antibody in both fractions (Figure $5 f$ ). These results suggest that DNAJB9 interacts with p53 in both cytoplasm and nucleus under genotoxic conditions.
Together, these data suggest that DNAJB9 colocalizes and interacts with p53 in both cytoplasm and nucleus under genotoxic conditions.

DNAJB9 inhibits the pro-apoptotic function of p53 through a physical interaction. We next asked whether DNAJB9 could inhibit the pro-apoptotic function of p53 through a physical interaction. For this purpose, we transfected SK-N-SH cells with myc-DNAJB9 plasmids or an empty vector and then treated cells with doxorubicin. After $48 \mathrm{~h}$, the sub- $\mathrm{G}_{1}$ apoptotic cell population was measured by flow cytometry. The data showed that doxorubicin treatment increased sub- $\mathrm{G}_{1}$ cell population from 1.5 to $47.9 \%$ in vectortransfected cells. In contrast, myc-DNAJB9-FL, - NJ and -J reduced the apoptotic rates remarkably to $15.2 \%, 14.4 \%$ and $13.8 \%$, respectively. Myc-DNAJB9- $\mathrm{N}$ and $-\Delta \mathrm{J}$ had no significant effect on the apoptotic rates as compared with the vector ( $-\mathrm{N}, 46.4 \%$ and $-\Delta \mathrm{J}, 52.6 \%$; Figures $6 \mathrm{a}$ and $\mathrm{b}$ ). These results suggest that the $\mathrm{J}$ domain of DNAJB9 is critical
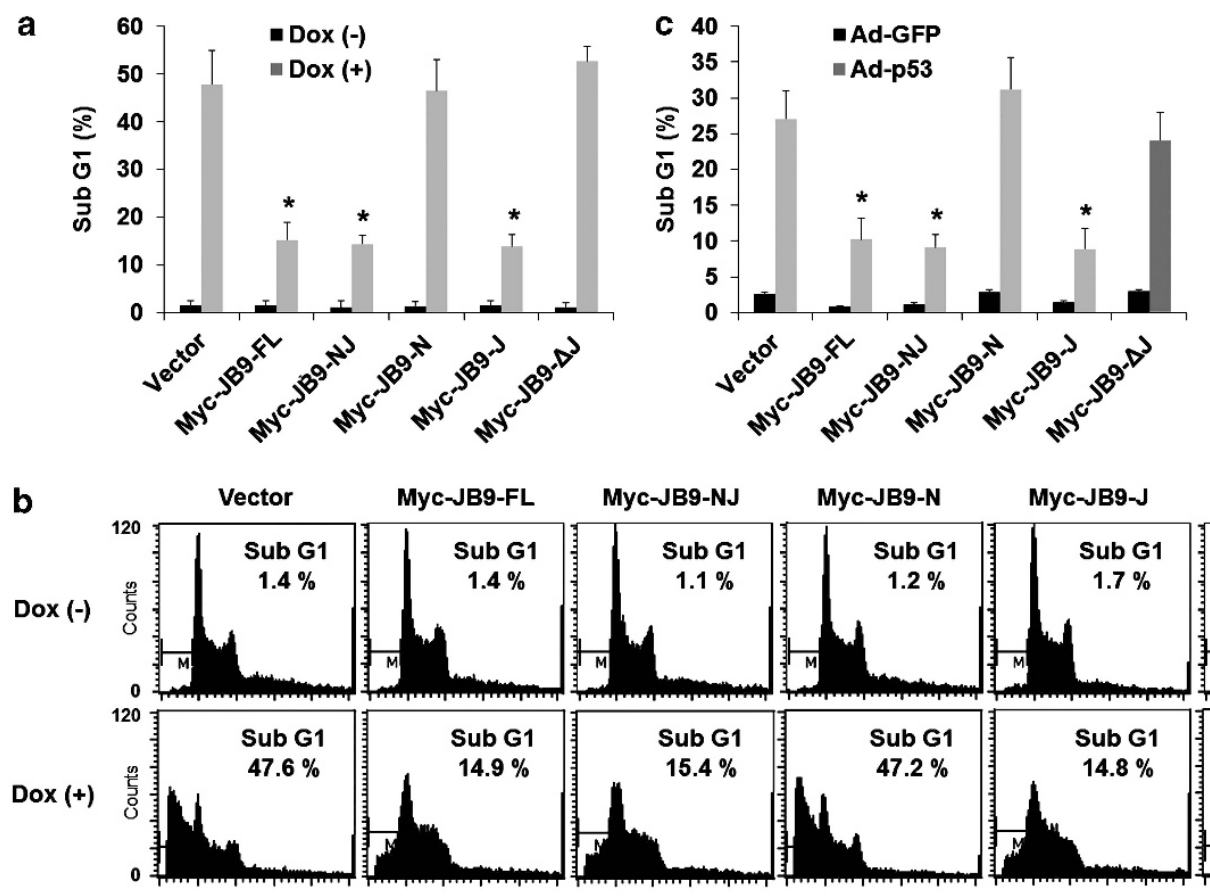

Myc-JB9-FL

Myc-JB9-NJ

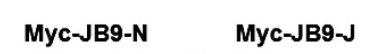

Myc-JB9- $\Delta \mathbf{J}$
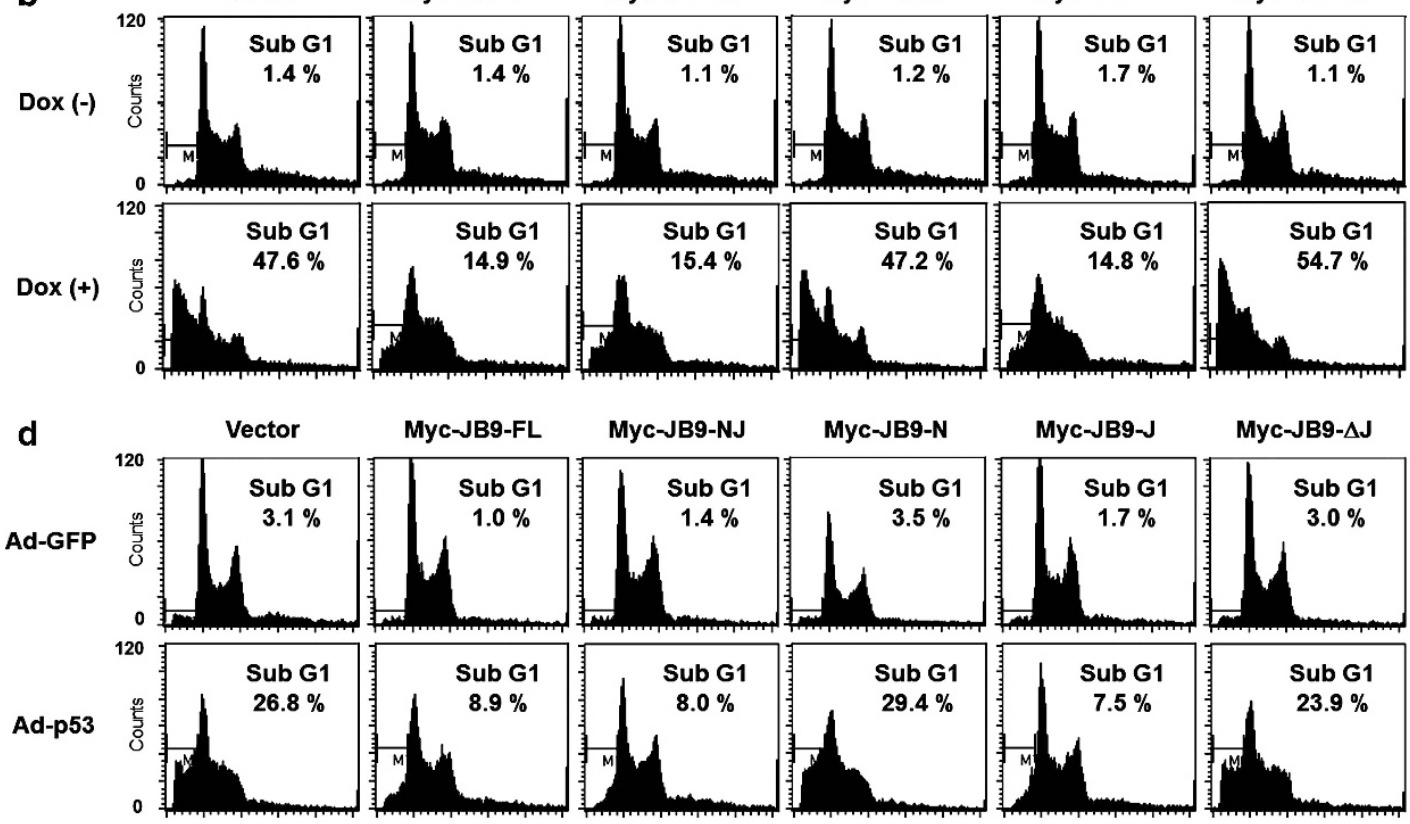

Figure 6 DNAJB9 inhibits the pro-apoptotic function of p53 through a physical interaction. (a) The J domain of DNAJB9 inhibits genotoxic stress-induced apoptosis. SK-N$\mathrm{SH}$ cells were transfected with expression vectors for myc-DNAJB9 deletion mutants or an empty vector (Vt), and then treated with $1 \mu \mathrm{M}$ of doxorubicin (Dox) for $48 \mathrm{~h}$. The sub$\mathrm{G}_{1}$ cell population was measured by flow cytometry. (b) Representative flow cytometry data of a are shown. (c) The J domain of DNAJB9 inhibits p53-induced apoptosis. SK-N$\mathrm{SH}$ cells were transfected with expression vectors for myc-DNAJB9 deletion mutants or an empty vector (Vt), and then infected by Ad-GFP or Ad-p53 for $48 \mathrm{~h}$. The sub-G 1 cell population was measured by flow cytometry. (d) Representative flow cytometry data of $\mathbf{c}$ are shown. Data represent averages \pm S.D. $\left({ }^{\star} P<0.05\right)$ 
to inhibit the p53-dependent apoptosis under genotoxic conditions.

To verify the effect of the $\mathrm{J}$ domain on the p53-dependent apoptosis, we analyzed the effect of the $\mathrm{J}$ domain on apoptosis triggered by p53 overexpression. SK-N-SH cells were transfected with myc-DNAJB9 plasmids or an empty vector and then infected by Ad-GFP or Ad-p53. After 48 h, cells were harvested and the apoptotic rates were measured by flow cytometry. The data showed that Ad-p53 infection triggered apoptotic response in vector-transfected cells as

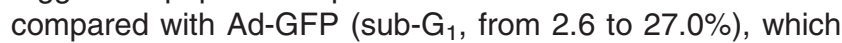
was remarkably inhibited by myc-DNAJB9-FL, - NJ and -J (10.2\%, 9.1\% and $8.9 \%$, respectively). Myc-DNAJB9-N and $-\Delta \mathrm{J}$ had no significant effect on the apoptotic rates $(31.2 \%$ and $24.1 \%$, respectively; Figures $6 \mathrm{~b}$ and $\mathrm{d}$ ). These results confirm that the $\mathrm{J}$ domain of DNAJB9 is critical to inhibit the p53-dependent apoptosis.

All these results demonstrate that the $\mathrm{J}$ domain of DNAJB9 is critical to inhibit the pro-apoptotic function of p53, suggesting that DNAJB9 inhibits the pro-apoptotic function of p53 through a physical interaction.

\section{Discussion}

p53 is an important tumor suppressor whose mutation is found in half of human cancers. In response to DNA damage, p53 is activated to induce cell cycle arrest, senescence or apoptosis, through which it prevents proliferation of cells harboring damaged DNA. ${ }^{24}$ Since p53 exerts these actions mainly via inducing the expression of its downstream target genes, it is indispensable to identify its downstream target genes and to characterize them for understanding the action mechanism of p53. In the present study, we have identified DNAJB9 as a novel inducible gene of p53.

Most known target genes of p53 including Bax and p21 have been shown to mediate p53 function such as cell cycle arrest or apoptosis under genotoxic conditions. Accumulating evidence, however, indicates that another group of target genes do not mediate but inhibit p53 function, thereby acting as negative feedback regulators of $\mathrm{p} 53 .^{25}$ For example, COP1, COX-2, DDR1, HB-EGF, Mdm2 and Pirh2 are induced by p53 but inhibit p53-dependent cell cycle arrest or apoptosis under genotoxic conditions. ${ }^{8-15}$ In the present study, we have identified DNAJB9 as a novel inducible gene of p53 that belongs to the group of negative feedback regulators of $p 53$.

We have shown here that DNAJB9 is induced by p53 through the Ras/Raf/ERK pathway. There is still a possibility that other signaling pathways are also involved in the DNAJB9 induction by $\mathrm{p} 53$. Given the results, however, that the DNAJB9 induction by p53 was almost completely abolished by DN-Ras, DN-Raf-1 and a MEK1/2 inhibitor (Figure 2), we reason that the Ras/Raf/ERK cascade is the main pathway to induce the DNAJB9 expression by p53. It has been previously reported that $\mathrm{p} 53$ activates the Ras/Raf/ERK pathway under genotoxic conditions ${ }^{14}$ and that COX-2, another downstream target of $\mathrm{p53}$, is induced by $\mathrm{p53/Ras/Raf/ERK}$ cascade, ${ }^{12}$ supporting our conclusion that the Ras/Raf/ERK pathway mediates the induction of DNAJB9 by p53. Further studies are required to understand the complete signaling networks by which p53 induces DNAJB9 expression.
Human DNAJB9 was first cloned in SK-N-SH cells as one of the genes induced by ER stressors such as tunicamycin and thapsigargin. ${ }^{21}$ The primary location of DNAJB9 is the $E R$, where it binds to BiP/GRP78, the major Hsp70 in the $\mathrm{ER}$, and stimulates the ATPase activity of $\mathrm{BiP} .{ }^{19}$ Although it has been recently proposed that DNAJB9 is involved in the ER-associated degradation of misfolded proteins, ${ }^{26}$ the cellular function of DNAJB9 is largely unknown. We here found a novel function of DNAJB9 under genotoxic conditions: DNAJB9 is induced by p53 and inhibits the proapoptotic function of p53 (Figures 1-3). A previous report that DNAJB9 inhibits tunicamycin-induced cell death in SK-N-SH cells supports our conclusion that DNAJB9 is a survival factor. ${ }^{21}$

We here found that DNAJB9 inhibits the pro-apoptotic function of $\mathrm{p} 53$ through a physical interaction and the physical interaction occurs in both cytoplasm and nucleus under genotoxic conditions (Figures 4-6). These findings suggest a possibility that the cytoplasmic interaction between DNAJB9 and p53 might promote the degradation of p53. However, our data showed that depletion of DNAJB9 by siRNAs rather decreased p53 levels under genotoxic conditions (Figures 3c, $\mathrm{d}$ and i) and DNAJB9 overexpression increased p53 levels (Supplementary Figure 2b), suggesting that DNAJB9 does not downregulate p53 levels.

Another possibility is that the cytoplasmic DNAJB9-p53 interaction might prevent the nuclear translocation of $\mathrm{p} 53$. Actually, we observed that nuclear translocation of p53 was increased by DNAJB9 siRNAs but decreased by DNAJB9 overexpression (Supplementary Figures $3 a$ and b). In addition, confocal data showed that DNAJB9 overexpression attenuates the nuclear translocation of p53 under doxorubicin treatment (Supplementary Figure 3c). These data suggest that the cytoplasmic DNAJB9-p53 interaction inhibits the nuclear translocation of $\mathrm{p53}$, which could be one of the mechanisms by which DNAJB9 inhibits the pro-apoptotic function of $\mathrm{p} 53$.

Nonetheless, the confocal data also showed that DNAJB9 did not sequester p53 in the cytoplasm completely and the majority of p53 still translocated to the nucleus under doxorubicin treatment (Supplementary Figure 3c), suggesting that the cytoplasmic DNAJB9-p53 interaction is not the main mechanism by which DNAJB9 inhibits the pro-apoptotic function of p53. In addition, we observed that DNAJB9 abolished the p53 binding to the Bax promoter under doxorubicin treatment in chromatin immunoprecipitation assays (Supplementary Figure $3 d$ ). Therefore, we assume that the nuclear DNAJB9-p53 interaction might be a major mechanism by which DNAJB9 inhibits the pro-apoptotic function of p53. Further studies are necessary to test this possibility and to elucidate the function of DNAJB9 in the nucleus.

DNAJB9 is an ER-resident protein. In some conditions, however, DNAJB9 has been found in another compartment. For example, GFP-fused DNAJB9 was observed to translocate to the nucleus under the treatment of heat shock and methanol in COS-7 and HeLa cells. ${ }^{20,22}$ We report here that genotoxic stress is another cause to localize DNAJB9 in the nucleus (Figure 5). Further studies are required to elucidate the mechanism of how DNAJB9 enters the nucleus. 


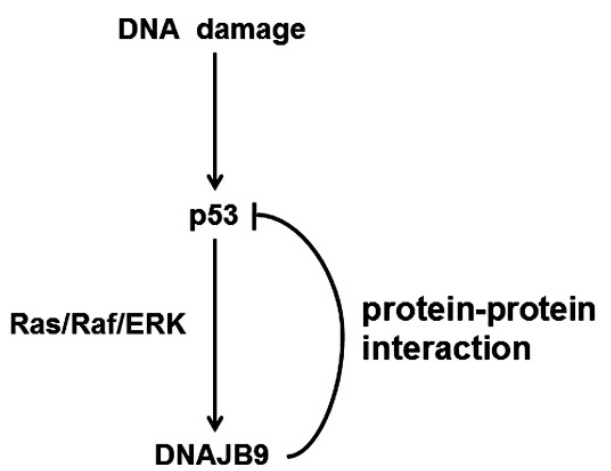

Figure 7 A biochemical link between DNAJB9 and p53 under genotoxic conditions

Collectively, we have established a biochemical link between DNAJB9 and p53 under genotoxic conditions. DNAJB9 is a downstream target of p53 and acts as a negative feedback regulator of p53 through a physical interaction (Figure 7). This study might contribute to understand action mechanisms of p53 and cellular functions of DNAJB9 under genotoxic conditions.

\section{Materials and Methods \\ Plasmids, siRNAs and adenoviruses. Mammalian expression vectors for DN-Ras (H-RasN17) $)^{27}$ and Raf-1 (K375M) ${ }^{28}$ were generous gifts from Dr. Sam W Lee (Massachusetts General Hospital, Boston, MA, USA). The oligonucleotide sequences of siRNAs used in this study were: si-control, $3^{\prime}$-CCUACGCCACCAAU UUCGU-5'; si-JB9 \#1, 3'-ACACGUAAUUUUGCCUAGU-5'; si-JB9 \#2, 3'-CACUC UUAGGUCUUAGUAU-5'; si-JB9 \#3, 3'-ACGAAGAGGAAATATGGTT-5'. Adeno- viruses expressing GFP and p53 were generated and amplified as described previously. ${ }^{29,30}$}

Generation of a polyclonal anti-DNAJB9 antibody. A rabbit polyclonal antibody was raised against a synthetic peptide, AC-G-F-D-S-T-N-QH-T-V-Q-T-E-N-R-F-H-G-S-S-K-H-C, corresponding to residues 181-203 of human DNAJB9, as described previously. ${ }^{21}$ The antibody was purified using a protein A agarose affinity column (Upstate, Lake Placid, NY, USA).

Cell culture and transfection. SK-N-SH (human neuroblastoma), U2OS (human osteosarcoma), $\mathrm{H} 1299$ (human lung cancer), p53(+ / +) and p53(-I-) MEFs were cultured in Dulbecco's modified Eagle's medium containing fetal bovine serum $(10 \%)$ and penicillin/streptomycin (1\%) in a $5 \% \mathrm{CO}_{2}$ incubator. EJ-p53 cells were cultured in the above medium in the presence of tetracycline $(1 \mu \mathrm{g} / \mathrm{ml})$ as described previously. ${ }^{12}$ For transfection of plasmids and siRNAs, cells were seeded into $60-\mathrm{mm}$ dishes and the transient transfection was performed using Lipofectamine2000 reagent (Invitrogen, Carlsbad, CA, USA).

FACS analysis. Cells were collected and resuspended in $1 \mathrm{ml}$ cold PBS. Ethanol, pre-chilled at $-20^{\circ} \mathrm{C}$, was added to cells drop wise with gentle vortexing. The resultant mixture was incubated at $4^{\circ} \mathrm{C}$ overnight. The following day, cells were washed with $10 \mathrm{ml}$ ice-cold PBS and permeabilized in a reagent consisting of $100 \mu \mathrm{g} / \mathrm{ml}$ RNase A and $50 \mu \mathrm{g} / \mathrm{ml}$ propidium iodide in PBS. Samples were incubated at $37^{\circ} \mathrm{C}$ for $1 \mathrm{~h}$ and then analyzed by flow cytometry (FACScan, Becton Dickinson, Franklin Lakes, NJ, USA). The sub-G $\mathrm{G}_{1}$ cell population was measured using the CellQuest program (Becton Dickinson). ${ }^{12}$

Confocal microscopy. Cells were seeded onto 18-mm coverslips and cultured overnight. The following day, cells were fixed in a 3.7\% formaldehyde solution and permeabilized in a $0.2 \%$ Triton X-100 solution. The cells were incubated with the antibody for DNAJB9 or p53 (FL-393, Santa Cruz Biotechnology, Dallas, TX, USA) for $2 \mathrm{~h}$ and then with a FITC-conjugated antirabbit IgG (Sigma, St. Louis, MO, USA) for $1 \mathrm{~h}$. After washing, nuclei were stained with DAPI (Sigma) for $5 \mathrm{~min}$ and images were taken with a confocal microscope (Olympus Fluoview, Olympus, Tokyo, Japan). ${ }^{29}$

Northern blot analysis. Total RNA was extracted from cells with Trizol reagent (Life Technologies, Carlsbad, CA, USA), resolved on 1\% formaldehyde-agarose gels and subsequently transferred to zeta-probe GT blotting membranes (Bio-Rad, Berkeley, CA, USA). Hybridization was performed using ${ }^{32}$ P-labeled probes, and the washed membranes were then subjected to autoradiography. ${ }^{29}$

Western blot analysis. Cells were lysed in a lysis buffer $(150 \mathrm{mM} \mathrm{NaCl}$, $50 \mathrm{mM}$ Tris- $\mathrm{HCl}, 1 \% \mathrm{NP}-40,0.25 \%$ sodium deoxycholate, and $0.1 \%$ SDS) with $1 \mathrm{mM}$ PMSF, $1 \mu \mathrm{g} / \mathrm{ml}$ aprotinin, $1 \mu \mathrm{g} / \mathrm{ml}$ leupeptin and $1 \mu \mathrm{g} / \mathrm{ml}$ pepstatin. Proteins were resolved on 10 or $12 \%$ SDS-polyacrylamide gels and transferred to PVDF membranes, which were probed with specific antibodies. The immunoreactive protein complexes were detected by enhanced chemiluminescence (Amersham Bioscience, Buckinghamshire, UK) ${ }^{29}$ The specific antibodies used in this study were: antibodies for p21, bax, cleaved caspase-3, ERK, p-ERK, p38, p-p38, JNK, p-JNK and PARP from Cell Signaling Technology (Danvers, MA, USA); an antip53 antibody (Ab-6) from Calbiochem (Billerica, MA, USA); anti-myc and antitubulin antibodies from Covance (Princeton, NJ, USA); and an anti- $\beta$-actin antibody from Sigma.

Subcellular fractionation. Cytoplasmic and nuclear fractions were prepared as described previously. ${ }^{29,31}$ Cells were washed with PBS and allowed to swell in buffer $A$ ( $10 \mathrm{mM}$ HEPES, pH 7.9, $10 \mathrm{mM} \mathrm{KCl}, 1 \mathrm{mM} \mathrm{DTT}, 1 \mathrm{mM}$ PMSF, $1 \mu \mathrm{g} / \mathrm{ml}$ leupeptin, $1 \mu \mathrm{g} / \mathrm{ml}$ aprotinin and $1 \mu \mathrm{g} / \mathrm{ml}$ pepstatin). After $15 \mathrm{~min}$, cells were lysed by adding NP-40 (final concentration, $0.5 \%$ ) and the nuclei were pelleted by centrifugation at $1500 \times g$ for $5 \mathrm{~min}$. The supernatant was centrifuged at $15000 \times g$ for $5 \mathrm{~min}$, and the cytoplasmic fraction was recovered. The nuclei were washed with buffer $A$ and resuspended in buffer $B$ (20 mM HEPES, pH 7.9, $0.4 \mathrm{M} \mathrm{NaCl}, 1 \mathrm{mM}$ DTT, $1 \mathrm{mM}$ PMSF, $1 \mu \mathrm{g} / \mathrm{ml}$ leupeptin, $1 \mu \mathrm{g} / \mathrm{ml}$ aprotinin and $1 \mu \mathrm{g} / \mathrm{ml}$ pepstatin). After incubation on ice for $15 \mathrm{~min}$, the nuclear fraction was recovered by centrifugation at $18000 \times g$ for $5 \mathrm{~min}$.

Immunoprecipitation. Cells were lysed in a lysis buffer $(50 \mathrm{mM}$ Tris- $\mathrm{HCl}, \mathrm{pH}$ $7.4,150 \mathrm{mM} \mathrm{NaCl}, 1 \% \mathrm{NP}-40,0.25 \%$ sodium deoxycholate, $0.1 \% \mathrm{SDS}, 50 \mathrm{mM} \mathrm{NaF}$, $1 \mathrm{mM}$ sodium orthovanadate and a protease inhibitor cocktail) by passage through a 22G needle (Tae-Chang, Kongju, South Korea). The cell lysates were immunoprecipitated with an antibody against DNAJB9 or p53 (FL-393, Santa Cruz Biotechnology) at $4{ }^{\circ} \mathrm{C}$, then mixed with Protein $\mathrm{A} / \mathrm{G}$ PLUS-agarose beads (Santa Cruz Biotechnology) for $2 \mathrm{~h}$. The beads were then washed three times with the lysis buffer, and bound proteins were subjected to SDS-PAGE and Western blot analysis. ${ }^{29}$

Chromatin immunoprecipitation. Chromatin immunoprecipitation assays were performed according to the manufacturer's instruction (Upstate). Briefly, cells were fixed with $1 \%$ formaldehyde and the cell pellet was sonicated in a lysis buffer. After centrifugation, the supernatant was diluted, pre-cleared and mixed with $2 \mu \mathrm{g}$ of an anti-p53 antibody (FL-393) or normal rabbit serum at $4{ }^{\circ} \mathrm{C}$ overnight. The next day, samples were mixed with protein A agarose/salmon sperm DNA for $1 \mathrm{~h}$ at $4{ }^{\circ} \mathrm{C}$ and the beads were washed several times. An elution buffer was added and the eluate was treated with $0.2 \mathrm{M} \mathrm{NaCl}$ for $4 \mathrm{~h}$ at $65^{\circ} \mathrm{C}$ and then proteinase $\mathrm{K}$ for $1 \mathrm{~h}$ at $45^{\circ} \mathrm{C}$. DNA was recovered by phenol/chloroform extraction and amplified by polymerase chain reaction using primers specific for the human Bax promoter. Sequences were $5^{\prime}$-TAATCCCAGCGCTTTGGAAG-3' (forward) and 5'-TGCAGA GACCTGGATCTAGC- $3^{\prime}$ (reverse) as described previously. ${ }^{32}$

Statistical analysis. Comparisons between groups were evaluated by the student's t-test using the Excel program (Microsoft Co., Redmond, WA, USA). Differences between groups were considered statistically significant when the $P$-values were $\leq 0.05$.

\section{Conflict of Interest}

The authors declare no conflict of interest.

Acknowledgements. We thank Dr. SW Lee for invaluable DNAs and cells. This research was supported by the Basic Science Research Program through the National Research Foundation of Korea (NRF) funded by the Ministry of Education, Science and Technology (2010-0007188).

1. Buckbinder L, Talbott R, Velasco-Miguel S, Takenaka I, Faha B, Seizinger BR et al. Induction of the growth inhibitor IGF-binding protein 3 by p53. Nature 1995; 377: 646-649. 
2. Attardi LD, Reczek EE, Cosmas C, Demicco EG, McCurrach ME, Lowe SW et al. PERP, an apoptosis-associated target of p53, is a novel member of the PMP-22/gas3 family. Genes Dev 2000; 14: 704-718.

3. Lin Y, Ma W, Benchimol S. Pidd, a new death-domain-containing protein, is induced by p53 and promotes apoptosis. Nat Genet 2000; 26: 122-127.

4. Oda E, Ohki R, Murasawa H, Nemoto J, Shibue T, Yamashita T et al. Noxa, a BH3-only member of the Bcl-2 family and candidate mediator of p53-induced apoptosis. Science 2000; 288: 1053-1058.

5. Nakano K, Vousden KH. PUMA, a novel proapoptotic gene, is induced by p53. Mol Cell 2001; 7: 683-694.

6. Wu GS, Burns TF, McDonald ER 3rd, Jiang W, Meng R, Krantz ID et al. KILLER/DR5 is a DNA damage-inducible p53-regulated death receptor gene. Nat Genet 1997; 17: 141-143.

7. Miyashita T, Reed JC. Tumor suppressor p53 is a direct transcriptional activator of the human bax gene. Cell 1995; 80: 293-299.

8. Honda R, Tanaka H, Yasuda H. Oncoprotein MDM2 is a ubiquitin ligase E3 for tumor suppressor p53. FEBS Lett 1997; 420: 25-27.

9. Leng RP, Lin Y, Ma W, Wu H, Lemmers B, Chung S et al. Pirh2, a p53-induced ubiquitinprotein ligase, promotes p53 degradation. Cell 2003; 112: 779-791.

10. Dornan D, Wertz I, Shimizu H, Arnott D, Frantz GD, Dowd P et al. The ubiquitin ligase COP1 is a critical negative regulator of p53. Nature 2004; 429: 86-92.

11. Ongusaha PP, Kim Jl, Fang L, Wong TW, Yancopoulos GD, Aaronson SA et al. p53 induction and activation of DDR1 kinase counteract p53-mediated apoptosis and influence p53 regulation through a positive feedback loop. EMBO J 2003; 22: 1289-1301.

12. Han JA, Kim JI, Ongusaha PP, Hwang DH, Ballou LR, Mahale A et al. P53-mediated induction of Cox-2 counteracts p53- or genotoxic stress-induced apoptosis. EMBO J 2002; 21: $5635-5644$.

13. Choi EM, Heo Jl, Oh JY, Kim YM, Ha KS, Kim Jl et al. COX-2 regulates p53 activity and inhibits DNA damage-induced apoptosis. Biochem Biophys Res Commun 2005; 328: $1107-1112$.

14. Lee SW, Fang L, Igarashi M, Ouchi T, Lu KP, Aaronson SA. Sustained activation of Ras/ Raf/mitogen-activated protein kinase cascade by the tumor suppressor p53. Proc Nat Acad Sci USA 2000; 97: 8302-8305

15. Fang L, Li G, Liu G, Lee SW, Aaronson SA. p53 induction of heparin-binding EGF-like growth factor counteracts $\mathrm{p} 53$ growth suppression through activation of MAPK and PI3K Akt signaling cascades. EMBO J 2001; 20: 1931-1939.

16. Houry WA. Chaperone-assisted protein folding in the cell cytoplasm. Curr Protein Pept Sci 2001; 2: 227-244.

17. Qiu XB, Shao YM, Miao S, Wang L. The diversity of the DnaJ/Hsp40 family, the crucial partners for Hsp70 chaperones. Cell Mol Life Sci 2006; 63: 2560-2570.
18. Vos MJ, Hageman J, Carra S, Kampinga HH. Structural and functional diversities between members of the human HSPB, HSPH, HSPA, and DNAJ chaperone families. Biochemistry 2008; 47: 7001-7011.

19. Shen $Y$, Meunier L, Hendershot LM. Identification and characterization of a novel endoplasmic reticulum (ER) DnaJ homologue, which stimulates ATPase activity of BiP in vitro and is induced by ER stress. J Biol Chem 2002; 277: 15947-15956.

20. Berger BJ, Muller TS, Buschmann IR, Peters K, Kirsch M, Christ B et al. High levels of the molecular chaperone Mdg1/ERdj4 reflect the activation state of endothelial cells. Exp Cell Res 2003; 290: 82-92.

21. Kurisu J, Honma A, Miyajima H, Kondo S, Okumura M, Imaizumi K. MDG1/ERdj4, an ERresident DnaJ family member, suppresses cell death induced by ER stress. Genes Cells 2003; 8: 189-202.

22. Prols F, Mayer MP, Renner O, Czarnecki PG, Ast M, Gassler C et al. Upregulation of the cochaperone Mdg1 in endothelial cells is induced by stress and during in vitro angiogenesis. Exp Cell Res 2001; 269: 42-53.

23. Sugrue MM, Shin DY, Lee SW, Aaronson SA. Wild-type p53 triggers a rapid senescence program in human tumor cells lacking functional p53. Proc Natl Acad Sci USA 1997; 94: 9648-9653.

24. Vogelstein B, Lane D, Levine AJ. Surfing the p53 network. Nature 2000; 408: 307-310.

25. Janicke RU, Sohn D, Schulze-Osthoff K. The dark side of a tumor suppressor: antiapoptotic p53. Cell Death Differ 2008; 15: 959-976.

26. Dong M, Bridges JP, Apsley K, Xu Y, Weaver TE. ERdj4 and ERdj5 are required for endoplasmic reticulum-associated protein degradation of misfolded surfactant protein $\mathrm{C}$. Mol Biol Cell 2008; 19: 2620-2630.

27. Lange-Carter CA, Johnson GL. Ras-dependent growth factor regulation of MEK kinase in PC12 cells. Science 1994; 265: 1458-1461.

28. Dent $P$, Reardon DB, Morrison DK, Sturgill TW. Regulation of Raf-1 and Raf-1 mutants by Rasdependent and Ras-independent mechanisms in vitro. Mol Cell Biol 1995; 15: 4125-4135.

29. Choi EM, Kim SR, Lee EJ, Han JA. Cyclooxygenase-2 functionally inactivates p53 through a physical interaction with p53. Biochim Biophys Acta 2009; 1793: 1354-1365.

30. He TC, Zhou S, da Costa LT, Yu J, Kinzler KW, Vogelstein B. A simplified system for generating recombinant adenoviruses. Proc Natl Acad Sci USA 1998; 95: 2509-2514.

31. Qu L, Huang S, Baltzis D, Rivas-Estilla AM, Pluquet O, Hatzoglou M et al. Endoplasmic reticulum stress induces p53 cytoplasmic localization and prevents p53-dependent apoptosis by a pathway involving glycogen synthase kinase-3beta. Genes Dev 2004; 18 : 261-277.

32. Kaeser MD, Iggo RD. Chromatin immunoprecipitation analysis fails to support the latency model for regulation of p53 DNA binding activity in vivo. Proc Natl Acad Sci USA 2002; 99: $95-100$.

\section{Supplementary Information accompanies this paper on Cell Death and Differentiation website (http://www.nature.com/cdd)}

